\title{
Impact of wealth status on health outcomes in Pakistan
}

A.Y. Alam, ${ }^{1}$ S. Nishtar, ${ }^{2}$ S. Amjad ${ }^{3}$ and K.M. Bile

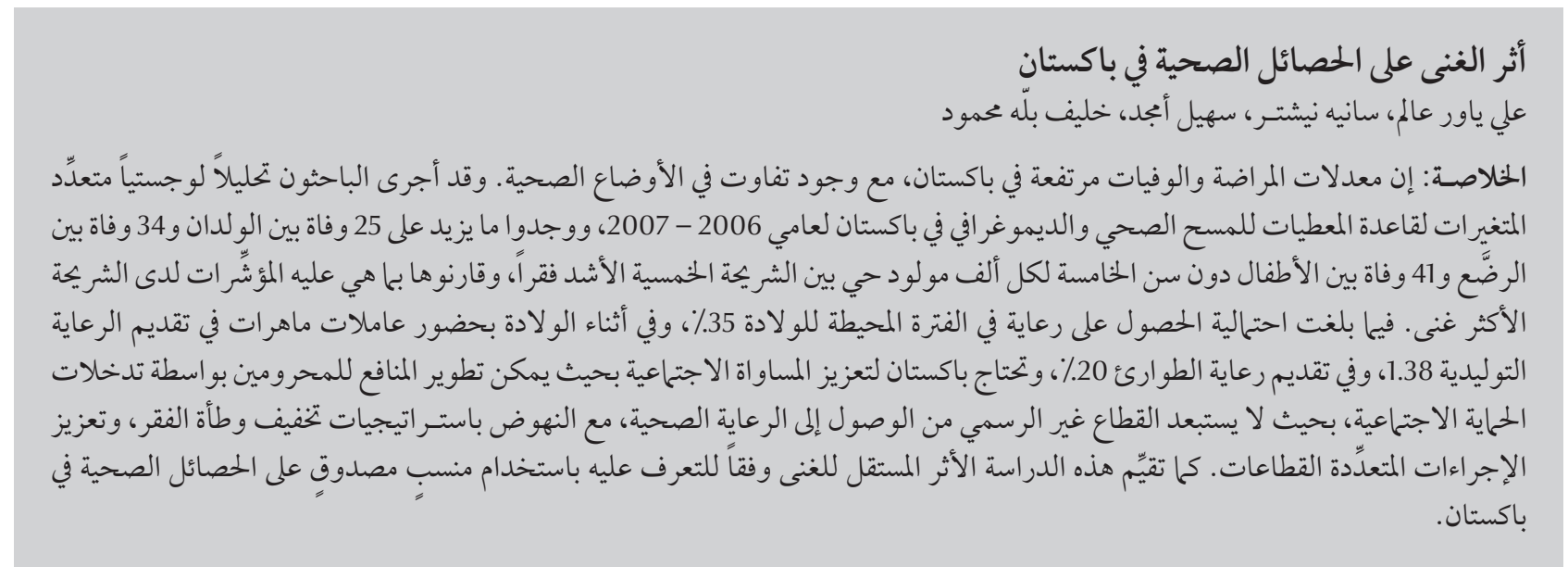

ABSTRACT Maternal and childhood morbidity and mortality are high in Pakistan and health disparities exist. Multivariate logistic regression analysis of the Pakistan Demographic and Health Survey database 2006-07 was performed. There was an excess of 25 neonatal, 34 infant and 41 under-five deaths per 1000 live births in the poorest quintile of wealth index compared with the richest. Women in the richest quintile had a 35\%, 38\% and $20 \%$ higher probability of getting prenatal care, delivery by skilled provider and emergency obstetric care, respectively. Pakistan needs to enhance social equity so development benefits can accrue to the underprivileged by introducing social protection interventions so that those in the informal sector are not excluded from accessing health care, scaling-up poverty reduction strategies and promoting intersectoral action. This study assesses the independent impact of wealth status, as determined by a validated index, on health outcomes in Pakistan.

\section{Statut économique et impact sur les résultats sanitaires au Pakistan}

RÉSUMÉ Au Pakistan, la mortalité et la morbidité maternelles et infantiles sont élevées, et des disparités sanitaires ont été observées. Une analyse de régression logistique multivariée a été effectuée sur la base de données 2006 2007 de l'Enquête démographique et de santé au Pakistan. Le quintile le plus pauvre (selon l'indice de richesse) était touché par une surmortalité de 25 nouveau-nés, 34 nourrissons et 41 enfants de moins de cinq ans pour 1000 naissances vivantes, par rapport au quintile le plus riche. Les femmes appartenant au quintile le plus riche avaient une probabilité plus élevée de $35 \%$ de bénéficier de soins prénatals, de 38 \% d'avoir un accouchement encadré par un professionnel qualifié et de 20 \% de recevoir des soins obstétriques d’urgence. Le Pakistan doit améliorer l'équité sociale pour que les bénéfices de cette amélioration puissent profiter aux plus défavorisés en mettant en place des interventions de protection sociale permettant de ne pas exclure le secteur non structuré de l'accès aux soins de santé, en élargissant les stratégies de réduction de la pauvreté et en encourageant une action intersectorielle. Cette étude évalue l'impact indépendant du statut économique sur les résultats sanitaires au Pakistan, selon une échelle validée. 


\section{Introduction}

There is a fundamental difference between inequality and inequity. The former is characterized by the determinants of health differentials between population groups or individuals that are related to biological variations (e.g. genetic predisposition to disease) and freely chosen health-damaging behaviours (e.g. smoking). On the other hand, health inequities, which have been variably defined, stem from health-damaging conditions and determinants that are not based on informed choices and could be avoided.

The World Health Organization (WHO) defines health inequity as "Differences in health status which are unnecessary and avoidable, but in addition, are considered unfair and unjust" [1]. The WHO Commission on Social Determinants of Health further adds "Health equity is about equitable distribution of health services in the society and that means distribution in conformity with where the needs are greatest" [2]. Another source adds that "Equity in health is the absence of disparities in the major social determinants of health" [3]. The concept of horizontal equity states "Equity in health services implies that there are no differences in health services where health needs are equal", while the concept of vertical equity emphasizes "that enhanced health services are provided where greater health needs are present" [1]. Equity in policy and actions refers to "active policy decision and programmatic action directed at improving equity in health" [1]. Equity in research highlights "research to elucidate the genesis and characteristics of inequity in health for the purpose of identifying factors amenable to policy decisions and programmatic actions" [1].

The determinant-based approach to health inequities and broader issues implicit in the social determinants of health (e.g. education, occupation, income) came significantly to the fore as factors determining health status with the publication of the report of the Commission on the Social Determinants of Health, which firmly established that inequities in daily living conditions and inequitable distribution of power, money and resources are the most important determinants of health status achievement [2]. As opposed to the analysis of inequities through the social determinants approach, the majority of published literature on equity in health focuses on access, utilization and financing of health services, the extent of primary health care services, geographic distribution and mix of health services.

Health systems performance assessment is an area where normative guidance is currently being consolidated [4]. However, experiences of countries that have developed health systems performance assessment frameworks recommend that assessment of inequities is an increasingly challenging area due to paucity of evidence. The framework for health systems performance assessment in Pakistan identified only a handful of studies that had examined inequities [Unpublished data]. Data from the Pakistan Social and Living Standards Measurement Survey give an insight into prevailing social sector inequities by wealth quintiles [5]. The same survey shows that the overall national infant mortality rate for urban areas was 45 per 1000 live births whereas for rural areas it was 79 per 1000 live births. In addition, rural-urban inequities and disparities were evident in these data trends. While there has been an increase in safe drinking water supply and adequate sanitation facilities in Pakistan between 1991 and 2007, the wide rural-urban differences have not narrowed [5].

Existing evidence of inequities also comes from WHO's multicountry assessment of inequities [6]. In this study the authors constructed a global asset score taking account of all the countries with demographic health survey (DHS) databases, include Pakistan, using four variables that were common to most countries with DHS data: urban-rural status, house construction material (usually floor material), educational status of the mother and availability of electricity. The lower the asset score, the higher is the probability (or prevalence in aggregate terms) of child malnutrition. The authors assumed that the average prevalence of malnutrition for children with the lowest $31 \%$ of asset scores equated to the prevalence of malnutrition for those living on less than US\$ 1 per day.

The above-mentioned studies have demonstrated the existence of inequities in health outcomes with reference to rural-urban and geographic status of residence and wealth status as determined by income quintiles. However, the independent effect of wealth on health outcomes has never been ascertained in the Pakistani indigenous setting. The present study was conducted to assess the independent impact of wealth status (as determined by a validated index) on health outcomes.

\section{Methods}

The 2006-07 Pakistan Demographic and Health Survey (PDHS), which was part of the worldwide demographic and health survey project, was the largest household survey ever conducted in Pakistan to gather information on health and demographic outcomes. Its methodology has been published elsewhere [7].

PDHS used a validated wealth index, which was developed and tested in a large number of countries in relation to inequalities in household income $[8,9]$. The index, which is fairly widely used as a measure of economic status in developing countries, is an indicator of the level of wealth that is consistent with expenditure and income measures [8]. This index was constructed using household asset data, including ownership of a number of consumer items ranging from a television to a bicycle 
or car, as well as dwelling characteristics, such as type of material used for flooring, source of drinking water and sanitation facilities. Each asset was assigned a weight (factor score) generated through principal components' analysis and the resulting asset scores were standardized in relation to a normal distribution with a mean of zero and standard deviation of one. Each household was then assigned a score for each asset and the scores were summed for each household; individuals were ranked according to the score of the household in which they resided. The sample was then divided into quintiles from one (poorest) to five (richest). The index is fairly widely used as a measure of economic status in developing countries $[8,9]$.

Raw data obtained from PDHS 2006-07 were analysed using SPSS version 10.0 and STATA version 9.0. This dataset was made available to researchers through an online registration system [10]. Three PDHS databases were used in this analysis. The maternal dataset consisted of 10023 women aged 12-49 years, representing all the provinces of Pakistan. The births dataset consisted of 39049 children, while the children's vaccination dataset consisted of 9177 children. In the PDHS, mothers were asked to show the interviewer the health cards of all children under the age of five years [8]. If a child had not received a health card, or if the mother was unable to show the card to the interviewer, the mother was asked to recall whether the child had received Bacille Calmette-Guérin (BCG), polio, diphtheria-pertussistetanus (DPT) (including the number of doses for polio and DPT) and measles vaccinations [7]. The births data were collected by asking ever-married women of reproductive age to provide complete birth histories of all their live births and those who had died [7].

Descriptive and analytical statistical analysis was carried out on all three datasets using SPSS version 10.0 and
STATA version 9.0. The lowest quintile (poorest) was used as the reference category and all comparisons were made with reference to that. In all three databases the variables controlled in the multivariate logistic regression model were as follows: rural-urban residence, wife's education, husband's education, wife's occupation and husband's occupation. For the birth and child databases, sex of the child was also additionally controlled for.

The study was not able to control for other confounding variables, such as health systems performance, access to health care and health-seeking behaviour.

Multivariate logistic regression was used to assess the impact of wealth status (as evidenced by wealth index quintiles). The adjusted odds ratios (OR) and $95 \%$ confidence intervals (CI) were obtained. Adjusted probabilities of each indicator variable across wealth index quintiles were obtained using the adjust command of STATA after the regression command.

\section{Results}

Health outcomes are affected by numerous factors. Figure 1 illustrates the conceptual framework of social determinants of health and other factors affecting health outcomes. Among the social determinants of health, level of education, occupation, income, wealth and rural-urban status are important. Outside of the social determinants, health systems performance, healthseeking behaviour and several factors in the intersectoral domain also influence health outcomes.

The distribution of children in the births database was 20269 (52\%) male children, while 24623 (63\%) children belonged to rural areas of Pakistan. The distribution of children according to quintiles of wealth index was as follows: poorest 8191 (21\%), poorer 8345 (21.4\%), middle 7957 (20.4\%), richer 7808 (20\%) and richest 6748 (17.3\%).

Table 1 shows the association of wealth index quintiles with child health outcomes. With reference to the

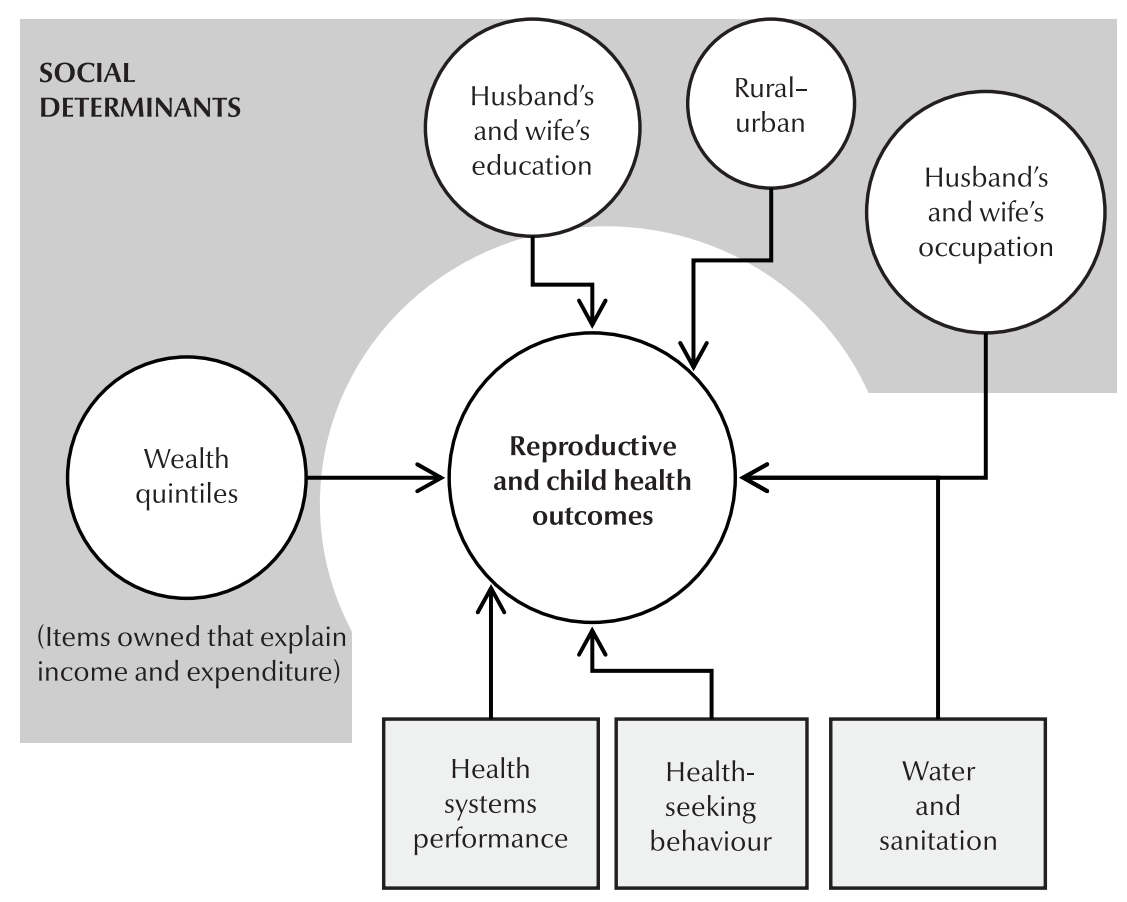

Figure 1 Conceptual framework of social determinants of health 


\begin{tabular}{|c|c|c|c|}
\hline Dependent variable & $\begin{array}{l}\text { Quintiles of } \\
\text { wealth index }\end{array}$ & $\begin{array}{l}\text { OR }(95 \% \mathrm{Cl}) \\
\text { adjusted }^{\mathrm{a}}\end{array}$ & $\begin{array}{l}\text { Adjusted }^{\mathrm{a}} \text { mortality rates } \\
\text { (per } 1000 \text { live births) }\end{array}$ \\
\hline \multirow[t]{5}{*}{ Neonatal mortality rate } & Poorest & 1.0 & 70 \\
\hline & Poorer & $0.98(0.87-1.11)$ & 63 \\
\hline & Middle & $0.76(0.67-0.87)$ & 56 \\
\hline & Richer & $0.68(0.58-0.79)$ & 50 \\
\hline & Richest & $0.67(0.55-0.82)$ & 45 \\
\hline \multirow[t]{5}{*}{ Infant mortality rate } & Poorest & 1.0 & 101 \\
\hline & Poorer & $0.93(0.84-1.03)$ & 92 \\
\hline & Middle & $0.75(0.67-0.84)$ & 83 \\
\hline & Richer & $0.72(0.64-0.82)$ & 75 \\
\hline & Richest & $0.66(0.56-0.78)$ & 67 \\
\hline \multirow[t]{5}{*}{ Under-five mortality rate } & Poorest & 1.0 & 116 \\
\hline & Poorer & $0.89(0.81-0.97)$ & 104 \\
\hline & Middle & $0.72(0.65-0.81)$ & 94 \\
\hline & Richer & $0.69(0.62-0.78)$ & 84 \\
\hline & Richest & $0.65(0.55-0.76)$ & 75 \\
\hline
\end{tabular}

${ }^{a}$ Adjusted for sex of child, rural-urban residence, wife's education, husband's education, wife's occupation, husband's occupation.

$O R=$ odds ratio; $C l=$ confidence interval.

poorest quintile of wealth index (OR $=1.0$ ) the adjusted ORs for middle, richer and richest categories of wealth index show a highly statistically significant lower odds of neonatal, infant and under-five child mortality. In absolute terms, adjusted neonatal mortality rates show an excess of 25 neonatal deaths per 1000 live births for neonates in the poorest quintile of wealth index compared with the richest quintile. Adjusted infant mortality rates show an excess of 34 infant deaths per 1000 live births for infants in the poorest quintile of wealth index compared with the richest quintile. Adjusted under-five child mortality rates show an excess of 41 under-five child deaths per 1000 live births in the poorest quintile of wealth index compared with the richest quintile.

Table 2 presents the association of wealth index quintiles with child health care services delivery. With reference to the poorest quintile of wealth index $(\mathrm{OR}=1.0)$ the adjusted $\mathrm{ORs}$ for poorer, middle, richer and richest categories of wealth index show a highly statistically significant higher odds of polio vaccine dose given at birth (polio 0), three husband's occupation. hepatitis $B$ virus. doses of DPT (DPT3), three doses of hepatitis B virus (HBV3) and measles vaccination. In absolute terms, adjusted probabilities of childhood vaccination status show that children in the richest quintile have an $18 \%$ higher probability of getting polio 0 vaccination, 19\% higher probability of getting DPT3 vaccination, $21 \%$ higher probability of getting HBV3 vaccination and $18 \%$ higher probability of getting measles vaccination.

Children in the richest quintile are 2.14 times more likely to get medical treatment for acute respiratory infections compared with children in the poorest quintile $(P<0.0001$, result not shown in table).

Table 3 shows the association of wealth index quintiles with reproductive health indicators. All the indicators of reproductive health show a higher OR favouring women in the richest quintile

\begin{tabular}{|c|c|c|c|}
\hline Dependent variable & $\begin{array}{l}\text { Quintiles of } \\
\text { wealth index }\end{array}$ & $\begin{array}{c}\text { OR }(95 \% \mathrm{Cl}) \\
\text { adjusted }^{\mathrm{a}}\end{array}$ & $\begin{array}{c}\text { Adjusted }^{\mathrm{a}} \\
\text { probabilities (\%) }\end{array}$ \\
\hline \multirow{5}{*}{$\begin{array}{l}\text { Polio } 0 \text { vaccination status among } \\
\text { under-five children }\end{array}$} & Poorest & 1.0 & 44 \\
\hline & Poorer & $1.26(1.11-1.43)$ & 49 \\
\hline & Middle & $1.41(1.23-1.63)$ & 53 \\
\hline & Richer & $1.61(1.37-1.89)$ & 58 \\
\hline & Richest & $2.13(1.73-2.62)$ & 62 \\
\hline \multirow{5}{*}{$\begin{array}{l}\text { DPT3 vaccination status among } \\
\text { under-five children }\end{array}$} & Poorest & 1.0 & 45 \\
\hline & Poorer & $1.25(1.10-1.42)$ & 50 \\
\hline & Middle & $1.49(1.30-1.72)$ & 55 \\
\hline & Richer & $1.79(1.52-2.11)$ & 60 \\
\hline & Richest & $2.22(1.80-2.75)$ & 64 \\
\hline \multirow{5}{*}{$\begin{array}{l}\text { HBV3 vaccination status among } \\
\text { under-five children }\end{array}$} & Poorest & 1.0 & 42 \\
\hline & Poorer & $1.24(1.09-1.41)$ & 47 \\
\hline & Middle & $1.55(1.35-1.79)$ & 52 \\
\hline & Richer & $1.88(1.59-2.21)$ & 58 \\
\hline & Richest & $2.18(1.77-2.69)$ & 63 \\
\hline \multirow{5}{*}{$\begin{array}{l}\text { Measles vaccination status among } \\
\text { under-five children }\end{array}$} & Poorest & 1.0 & 45 \\
\hline & Poorer & $1.20(1.05-1.37)$ & 50 \\
\hline & Middle & $1.46(1.26-1.67)$ & 54 \\
\hline & Richer & $1.81(1.53-2.13)$ & 58 \\
\hline & Richest & $1.83(1.48-2.24)$ & 63 \\
\hline
\end{tabular}

${ }^{a}$ Adjusted for sex of child, rural-urban residence, wife's education, husband's education, wife's occupation,

$O R=$ odds ratio; $C l=$ confidence interval; $D P T 3=3$ doses of diphtheria-pertussis-tetanus; $\mathrm{HBV} 3=3$ doses of 


\begin{tabular}{|c|c|c|c|}
\hline Dependent variable & $\begin{array}{l}\text { Quintiles of wealth } \\
\text { index }\end{array}$ & $\begin{array}{l}\text { OR }(95 \% \mathrm{CI}) \\
\text { adjusted }^{\mathrm{a}}\end{array}$ & $\begin{array}{c}\text { Adjusted }^{\mathrm{a}} \\
\text { probability (\%) }\end{array}$ \\
\hline \multirow{5}{*}{$\begin{array}{l}\text { Prenatal care from skilled } \\
\text { provider }\end{array}$} & Poorest & 1.0 & 45 \\
\hline & Poorer & $1.49(1.26-1.76)$ & 56 \\
\hline & Middle & $1.95(1.62-2.34)$ & 66 \\
\hline & Richer & $3.30(2.67-4.09)$ & 75 \\
\hline & Richest & $6.99(5.21-9.38)$ & 82 \\
\hline \multirow{5}{*}{$\begin{array}{l}\text { Tetanus injection (two doses) } \\
\text { before birth of child }\end{array}$} & Poorest & 1.0 & 61 \\
\hline & Poorer & $1.53(1.34-1.75)$ & 70 \\
\hline & Middle & $2.11(1.82-2.45)$ & 77 \\
\hline & Richer & $3.16(2.66-3.76)$ & 83 \\
\hline & Richest & $4.72(3.77-5.90)$ & 88 \\
\hline \multirow[t]{5}{*}{ Delivery by skilled ${ }^{\mathrm{b}}$ provider } & Poorest & 1.0 & 25 \\
\hline & Poorer & $1.44(1.19-1.75)$ & 33 \\
\hline & Middle & $1.86(1.52-2.28)$ & 43 \\
\hline & Richer & $3.02(2.43-3.76)$ & 53 \\
\hline & Richest & $5.40(4.16-7.01)$ & 63 \\
\hline \multirow{5}{*}{$\begin{array}{l}\text { Delivery in a clinic or } \\
\text { hospital }\end{array}$} & Poorest & 1.0 & 47 \\
\hline & Poorer & $1.47(1.29-1.67)$ & 57 \\
\hline & Middle & $1.88(1.64-2.16)$ & 66 \\
\hline & Richer & $2.99(2.56-3.50)$ & 74 \\
\hline & Richest & $5.73(4.68-7.01)$ & 80 \\
\hline \multirow{5}{*}{$\begin{array}{l}\text { Emergency obstetric care } \\
\text { availability in the last } \\
\text { delivery }\end{array}$} & Poorest & 1.0 & 42 \\
\hline & Poorer & $1.06(0.87-1.29)$ & 47 \\
\hline & Middle & $1.31(1.06-1.62)$ & 52 \\
\hline & Richer & $2.0(1.57-2.53)$ & 57 \\
\hline & Richest & $2.01(1.51-2.68)$ & 62 \\
\hline
\end{tabular}

${ }^{a}$ Adjusted for rural-urban residence, wife's education, husband's education, wife's occupation, husband's occupation.

${ }^{b}$ Skilled includes doctor, nurse, midwife or lady health worker.

$O R=$ odds ratio; $C l=$ confidence interval.

compared with women in the poorest quintile. All these adjusted associations are statistically highly significant. Women in the richest quintile were 7 times more likely to get prenatal care from a skilled provider, 4.7 times more likely to get two doses of tetanus injection before the birth of a child, 5.4 times more likely to have delivery by a skilled health care provider, 5.7 times more likely to have a delivery in a clinic or hospital and 2 times more likely to get emergency obstetric care (if need be) compared with women in the poorest quintile. In terms of absolute measures, adjusted probabilities show that women in the richest quintile have $35 \%$ higher probability of in the poorest quintile. In relation to educational attainment (primary or higher) the study showed that women in the richest quintile were 54.4 times more likely to attain this level compared with women in the poorest quintile.

\section{Discussion}

The dynamic link between per capita expenditure and health outcomes is well established [ 11$]$. This study aims to assess the independent impact of this association in Pakistan, as determined by a validated wealth index formulated by DHS. This index was constructed using household asset data, including ownership of a number of consumer items ranging from a television to a bicycle or car, as well as dwelling characteristics, such as type of material used for flooring and source of drinking water and sanitation facilities, while variables related to urban-rural status, wife's and husband's education and occupation were not included in this wealth index. Conversely, the variables of the global DHS asset score were used by a previous study on Pakistan considering urban-rural status, housing construction material (usually floor material), educational status of wives and availability of electricity with asset score ranking formulated by the authors [6]. However, the wealth index used by this paper was advantageous as the multivariate logistic regression analysis enabled us to control the effect of the aforementioned potential confounding factors.

Health outcomes are known to be influenced by a number of factors: biological, behavioural, socioeconomic, cultural, institutional and health systems performance related. The impact of socioeconomic factors on health and well-being has been well documented [11]. This is evidenced by differentials in life expectancy across regions of the world with different levels of economic development and mortality patterns according to the level of occupational 
hierarchy [11]. It is further evidenced by the observed differences in child mortality according to the income level of families and maternal level of education [11]. In many countries, the increased level of female education has been the single most important factor in decreasing child mortality $[12,13]$ Pakistan suffers an inherent disadvantage in this respect with high levels of poverty and illiteracy.

Inequities in health and other social outcomes have been described in the indigenous Pakistani population; however, the independent effect of wealth on health outcomes has not been assessed. The main value of this study lies in demonstrating that for the first time.

Although the study was not able to control for other confounding variables such as health systems performance, access to health care and health-seeking behaviour, it was able to control for a number of other variables such as rural-urban residence, and level of education and occupation of the head of the household. The differentials in outcomes are important evidence for health policy planners who predominantly focus on the health care perspective of interventions and often do not create the right linkages for intersectoral action.

The impact of factors outside the health care system on health outcomes can also be interpreted in another way - health care is limited in its ability to improve health status, unless the underlying socioeconomic conditions and inequities of power, money and resources change in the desirable direction [14]. It is precisely with this understanding in view that a recently articulated agenda for health reforms for Pakistan lays great emphasis on both the factors in the intersectoral domain as well as the overarching factors responsible for health systems performance [14]. Pakistan suffers a "double burden" in this respect. Not only are its social disparities widely prevalent, many overarching institutional impediments also act as a barrier for health systems performance.

Countries that have shown recent progress in improving child and maternal health indicators and that have experienced decreasing mortality and morbidity trends have made improvements on several fronts. Chile, a medium-resource country, is one such example. A consistent increase in annual per capita income and decrease in the number of people living in poverty between 1990 and 2004 are evidence of Chile's sustained economic growth $[15,16]$. In Chile, declines across maternal, newborn and child mortality indicators occurred in all five income quintiles, with the largest proportional decrease in the poorest quintile.

In Sri Lanka where a third of the population is estimated to live below the national poverty line, maternal morality ratios (44 per 100000 births in 2005) and under-five mortality rate (13 per 1000 in 2000) are among the lowest in the developing world [17]. All of this has been made possible by targeting the social determinants of health: free provision of health services to all, provision of maternal and child health care services at the community level, relatively high status of women, $88 \%$ literacy rate among women, girls having free access to education until university level, network of community midwives providing antenatal care to $75 \%$ of women, $96 \%$ skilled birth attendance rate, over $90 \%$ deliveries in health facilities, a strong referral system in place to ensure transport of women to one of the 45 hospitals if complications occur, and all first pregnancies and high-risk pregnancies referred to health facilities with obstetricians [14].

These findings parallel research in developed and transitional countries that has shown that reversals in marginalization patterns can result in overall improvements in survival and reductions in health care inequities $[18,19]$.

The debate on health reforms and the divergent views on the type of solutions needed centre on the issue of inequities in access to health care and the right to health, among other things. Equity assumes fundamental importance not only as an aspirational health goal but also, as being increasingly recognized, as one of the three desired health systems outcomes, the other two being fairness in financing and responsiveness.

\section{Conclusion}

These representative data from Pakistan quantify the burden of morbidity and mortality and access to health care associated with inequitable distribution of wealth in the society. The country will have to make progress by enhancing social equity so that the benefits of development can accrue to the underprivileged sections of the population. Social protection interventions should also be introduced so that those in the informal sector are not excluded from accessing health care, including: scaling-up the implementation of poverty reduction strategies and social sector investment, especially in health; promoting intersectoral action to achieve better health outcomes; and mitigating the ill effects of social determinants of health. The objective of this study is to assess the independent impact of wealth status, as determined by a validated index on health outcomes in Pakistan.

\section{Acknowledegment}

We are thankful to Yasir Abbas Mirza for the formatting and layout of this manuscript. 


\section{References}

1. Macinko JA, Starfield B. Annotated bibliography on equity in health, 1980-2001. International Journal for Equity in Health, 2002, 1(1):1.

2. Closing the gap in a generation: health equity through action on the social determinants of health. Final report of the Commission on Social Determinants of Health. Geneva, World Health Organization, 2008.

3. Braveman P, Gruskin S. Defining equity in health. Journal of Epidemiology and Community Health, 2003, 57(4):254-258.

4. Everybody's business: strengthening health systems to improve health outcomes: WHO's framework for action. Geneva, World Health Organization, 2007 (http://www.wpro.who.int/sites/ hsd/documents/Everybodys+Business.htm, accessed 16 December 2009).

5. Pakistan social and living standards measurement survey 2006 07. Islamabad, Federal Bureau of Statistics (http://www statpak.gov.pk/depts/fbs/statistics/pslm2006_07/report_ pslm06_07.pdf, accessed 24 July 2009).

6. Blakely T, Hales S, Woodward A. Poverty: assessing the distribution of health risks by socioeconomic position at national and local levels. Geneva, World Health Organization, 2004 (WHO Environmental Burden of Disease Series, No. 10).

7. Pakistan demographic and health survey 2006-07. Islamabad, National Institute of Population Studies and Macro International Inc., 2008.

8. Gwatkin DR et al. Socio-economic differences in health, nutrition, and population. Washington DC, World Bank, 2000.

9. Filmer D, Pritchett LH. Estimating wealth effects without expenditure data - or tears: an application to educational enrolments in states of India. Demography, 2001, 38(1):115-132.

10. Demographic and health surveys. Measure DHS. (http://www. measuredhs.com, accessed 25 September 2009).
11. Achieving health equity: from root causes to fair outcomes. Geneva, World Health Organization, Commission on the Social Determinants of Health, 2007 (http://whqlibdoc.who.int/ publications/2007/interim_statement_eng.pdf, accessed 23 June 2008).

12. Kaber N. Gender equality and human development: the instrumental rationale. Brighton, United Nation Development Programme, 2005 (http://www.hdr.undp.org/en/reports/ global/hdr2005/papers/hdr2005_kabeer_naila_31.pdf, accessed 25 June 2008).

13. Sri Lanka shines in slashing maternal, neonatal mortality: Unicef. (http://www.thaindian.com/newsportal/health/ sri-lanka-shines-in-slashing-maternal-neonatal-mortalityunicef_100142713.html, accessed 27April 2010).

14. Nishtar S. Choked pipes: reforming Pakistan's mixed health system. Karachi, Oxford University Press, 2010.

15. Bossert TJ et al. Decentralization and equity of resource allocation: evidence from Colombia and Chile. Bulletin of the World Health Organization, 2003, 81:95-100.

16. Gwatkin DR. Health inequalities and the health of the poor: what do we know? What can we do? Bulletin of the World Health Organization, 2000, 78:3-18.

17. Health a key to prosperity, success stories in developing countries. (http://www.who.int/inf-new/mate1.htm, accessed 27 April 2010).

18. Braveman P, Tarimo E. Social inequalities in health within countries: not only an issue for affluent nations. Social Science \& Medicine, 2002, 54:1621-1635.

19. The world health report 2005. Make every mother and child count Geneva, World Health Organization, 2005. 